\title{
The effect of pattern and texture gradient on slant and shape judgments'
}

\author{
AMY L. KRAFT AND WILMA A. WINNICK \\ QUEENS COLLEGE OF THE CITY UNIVERSITY OF NEW YORK
}

The experiment reported was designed to explore the relationship between gradient of texture and monocular slantshape perception. The effects of instructional set and order of slant and shape judgments were studied in interaction with four patterns differing in regularity of texture. Judgments of slant and shape were made by the same Ss for all patterns at $20^{\circ}, 45^{\circ}, 60^{\circ}$ slant for slant judgments and $0^{\circ}, 20^{\circ}, 45^{\circ}, 60^{\circ}$ for width judgments. There were three instructional groups. Within each group one half of the Ss made slant judgments first, the other half shape judgments first. For all patterns, accurate perception of the slant of patterned material resulted in increased compensation in width judgments. Apparent width was found to be a function of pattern and also subject to instructional manipulation.

Gibson (1950) demonstrated and Flock and Moscatelli (1964) have confirmed the finding that phenomenal slant is functionally related to the gradient of density of texture. This relationship was revealed by projecting photographic slides made from textures slanted at various angles; Ss' judgments of slant were found to increase with increases in the gradient of texture of the projected image. Furthermore, the effect was found to be greater for a regular texture than for irregular ones. His suggestion that texture, "...a speckled distribution of light in the retina...," is of aid in distinguishing between surfaces in the frontal plane, and surfaces that are slanted from the frontal plane may be applicable to shape judgments as well. In other words, if $\mathrm{S}$ is led by the gradient of texture to judge (non-veridically) that visual surface-shape is slanted, he may at the same time judge that its shape is other than it actually is. This would seem to be the implication of the shape-slant invariance hypothesis. More specifically, the implication is that a decrease in accuracy of judgments of slant will result in a similar decrease (in the same direction) in judgments of shape.

To test the shape-slant invariance hypothesis, Winnick and Rogoff (1965) obtained slant and width judgments in two experiments, using the same apparatus and the same stimulus materials. In support of the hypothesis, they found overestimations of slant (at the larger angles) to be accompanied by judgments of shape far from projected shape and underestimation, by judgments close to projected shape. Where shape and slant measures were taken under reduction conditions, Winnick and Rosen (1966) found shape-slant relations to be as predicted from the invariance hypothesis.
The present experiment used conditions of nonveridical slant in an attempt to replicate the textureslant relationship reported by Gibson (1950) and to test its relevance to shape (width) judgments. An apparatus permitting simultaneous viewing of the textured pattern and a comparison stimulus was used to overcome one of the criticisms of Epstein and Park (1963). Pursuing their suggestion that instructions might influence shape judgments, three different instructional groups were employed. The ordering of shape and slant judgments was an additional variable that preliminary experimentation suggested might be of relevance.

\section{Experimental design}

\section{METHOD}

Two kinds of judgments were made by each S. Slant estimations were made for the textural patterns, photographed at $20^{\circ}, 45^{\circ}$ and $60^{\circ}$. Width judgments were made using the same patterns and an additional
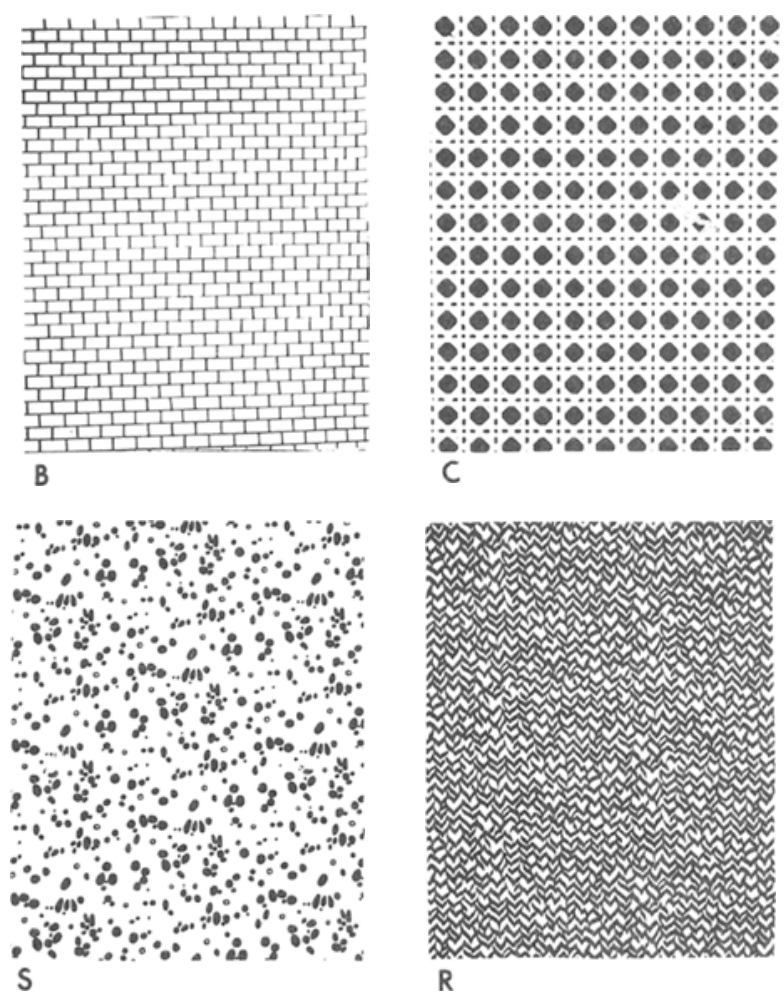

Fig. 1. The four pattems used for slant and width judgments, shown as photographed in frontal-parallel plane. 
Table 1

Summary Table for Slant and Shape Judgments, A-P Values

for Instructions $X$ Patterns $X$ Angles Interactions

\begin{tabular}{|c|c|c|c|c|c|c|c|c|c|c|c|c|}
\hline \multirow{2}{*}{$\begin{array}{l}\text { Verid } \\
\text { Angles } \\
\text { Patterns }\end{array}$} & \multirow[b]{2}{*}{ Instr. } & \multicolumn{2}{|l|}{$0^{\circ}$} & \multicolumn{3}{|c|}{$20^{\circ}$} & \multicolumn{3}{|c|}{$45^{\circ}$} & \multicolumn{3}{|c|}{$60^{\circ}$} \\
\hline & & $\begin{array}{c}\bar{M} \text { Shape } \\
\text { judg. }\end{array}$ & $a-p$ & $\begin{array}{l}\text { H Slant } \\
\text { judg. }\end{array}$ & 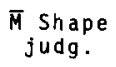 & $a-p$ & $\begin{array}{c}\bar{M} \operatorname{Slant} \\
\text { judg. }\end{array}$ & $\begin{array}{c}\bar{M} \text { Shape } \\
\text { judg. }\end{array}$ & $a-p$ & $\begin{array}{c}\text { H Slant } \\
\text { judg. }\end{array}$ & $\begin{array}{l}\text { M Shape } \\
\text { judg. }\end{array}$ & $a-p$ \\
\hline \multirow[t]{3}{*}{ Brick } & A & 3.72 & -.03 & 14.03 & 3.59 & .07 & 27.57 & 2.76 & -.11 & 40.24 & 1.91 & -.03 \\
\hline & B & 3.77 & .02 & 19.50 & 3.66 & .14 & 28.58 & 2.94 & .29 & 45.53 & 2.36 & .48 \\
\hline & $c$ & 3.76 & .01 & 20.53 & 3.75 & .23 & 28.05 & 3.19 & .54 & 44.49 & 2.67 & .79 \\
\hline \multirow[t]{3}{*}{ Cane } & A & 3.52 & -.23 & 20.89 & 3.65 & .13 & 38.78 & 2.93 & .28 & 42.03 & 2.24 & .36 \\
\hline & B & 3.53 & -.22 & 23.21 & 3.69 & .17 & 45.80 & 3.35 & .70 & 48.16 & 2.63 & .75 \\
\hline & $c$ & 3.56 & -.19 & 21.92 & 3.75 & .23 & 43.05 & 3.69 & 1.04 & 52.49 & 3.28 & 1.40 \\
\hline \multirow[t]{3}{*}{ Ripple } & A & 3.47 & -.28 & 10.63 & 3.37 & -.15 & 15.76 & 2.55 & -.10 & 22.18 & 1.65 & -.23 \\
\hline & $B$ & 3.50 & -.25 & 12.15 & 3.44 & -.08 & 19.10 & 2.56 & -.09 & 24.13 & 1.79 & -.09 \\
\hline & $\mathrm{C}$ & 3.42 & -.33 & 10.38 & 3.42 & -.10 & 16.54 & 2.75 & .10 & 27.49 & 2.08 & .20 \\
\hline \multirow[t]{3}{*}{ Splatter } & A & 3.74 & -.01 & 9.47 & 3.44 & -.08 & 16.56 & 2.57 & -.08 & 23.85 & 1.78 &. .10 \\
\hline & B & 3.70 & -.05 & 13.35 & 3.52 & .00 & 21.50 & 2.65 & .00 & 31.71 & 1.88 & .00 \\
\hline & $c$ & 3.51 & -.24 & 10.03 & 3.27 & -.25 & 20.93 & 2.90 & .25 & 27.36 & 2.19 & .31 \\
\hline \multicolumn{13}{|c|}{$\begin{array}{l}\text { Projected Shape } \\
\text { or Width in }\end{array}$} \\
\hline
\end{tabular}

pattern photographed in the frontal-parallel plane; these estimates were made by adjusting a comparison width to match the apparent width of the textured patterns. Within each of the three instructional groups, the two kinds of judgments were made in discrete blocks of trials with the order of slant and width balanced within each group; each $\mathrm{S}$ made 24 slant judgments and 32 width judgments, eight at each angle. Thus, experimental design is of "mixed" type, with two "between-Ss" effects (order and instructions) and two "within-Ss" effects (patterns and angle). The identical experimental design was used for both slant and width judgments.

Subjects. Sixty volunteer university undergraduates ranging from 17-20 years of age served as Ss. All had either normal vision without glasses or corrected vision with glasses; an additional criterion was the ability to distinguish the patterns at the 7-ft. distance required by the apparatus. Two Ss who did not meet this requirement were replaced.

Apparatus. The apparatus was arranged to present slides of the stimulus materials and to allow shape judgments to be made. It was designed to correspond as closely as possible with that described by Gibson (1950). The resemblance was limited by the requirements for shape judgments. The apparatus consisted of a black reduction tunnel constructed from plywood, measuring $7 \mathrm{ft}$. in its length, $12 \mathrm{in}$. in height and $18 \mathrm{in.} \mathrm{in} \mathrm{width.} \mathrm{A} \mathrm{stop} \mathrm{measuring} 1$ in., an eyepiece and a chinrest were centered at S's end of the tunnel and served to restrict vision to the stimulus materials. At the opposite end, a translucent plastic screen was stretched across the opening. It was held in place on the outside by a piece of black plywood. In this piece were cut two rectangular openings. The cutout on E's right hand side measured 5 in. high

by 3.75 in. wide; the cutout on the left could be varied in its width by the coordinated movement of two sliding doors and provided the basis for width judgments.

Stimulus materials were presented for slant or shape judgments in the form of slides whose images were projected through the translucent plastic from behind the box. Two projectors 10 in. from the openings in the back of the box were employed, one for exposure of the stimulus materials, the other to illuminate the variable opening used for width judgments. The resultant luminance within the reduction tunnel averaged $1.59 \mathrm{ft} .-\mathrm{L}$.

Stimulus materials. An effort was made to duplicate the texture patterns used by Gibson (1950). A linear brick pattern and an irregular splatter pattern were used to approximate those of the wall papers used by Gibson. A tweed pattern and a cane pattern, white on black, were added; these are shown in Fig. 1. Large pieces of these patterns were photographed in a frontal parallel position and at $20^{\circ}$, $45^{\circ}$ and $60^{\circ}$ from frontal position, and $35 \mathrm{~mm}$ slides were made from the photographs. The patterns appeared to slant away from the viewer on the right hand side, i.e., the textured density increased to the right. The slides were masked to yield rectangular shaped patterns, with width corresponding to the projected width at a given slant; these widths were 3.50 in. at $20^{\circ}$, 2.75 in. at $45^{\circ}$, and 1.75 in. at $60^{\circ}$. This eliminated the trapezoidal shape changes that accompany slant, leaving the gradient of texture density as the effective cue to slant. The lateral positioning of these rectangles was varied by masking the side of each slide differently.

Procedure. Observations of the stimulus materials were made monocularly with S's favored eye by looking through the eye piece. $S$ was told to indicate 
readiness to estimate the slant and made the estimate in standing position. Judgments of slant were made as $E$ gradually turned a rectangular slant board alternately away from the $\mathrm{S}$ or from a $90^{\circ}$ position toward him. The slant board was mounted on top of the reduction tunnel close to the back end and was illuminated by a goose-neck lamp. This procedure was followed for each $\mathrm{S}$ for the four patterns at three angles $\left(20^{\circ}, 45^{\circ}, 60^{\circ}\right)$. After a short rest interval, the procedure was repeated with a second random order giving a total of two judgments for each stimulus for each $S$. The data recorded were the angles read from the slant board protractor at the point of match for each $\mathrm{S}$.

All width judgments were made from a sitting position. When $\mathrm{S}$ looked into the box upon instruction, a patterned display appeared in the left field.

The right field was used to expose the comparison form; this was a light gray rectangle bounded by black movable doors that provided variation in width. This comparison field, uniformly gray, provided no textural information. Using the method of Average Error, E widened or narrowed the light gray comparison rectangle slowly, doubling back if necessary until $S$ judged the match of the comparison rectangle to the patterned display to be satisfactory. This procedure was used for each pattern at $0^{\circ}, 200,45^{\circ}$,

Table 2

Sumary Table of Analysis of Variance Performed on Mean Judgments of Slant

\begin{tabular}{|c|c|c|c|c|}
\hline Source & $d f$ & MS & $\mathrm{F}$ & $p$ \\
\hline Between Ss & 59 & & & \\
\hline order & 1 & 4,244 & - & - \\
\hline Instructions & 2 & 98,494 & - & - \\
\hline Order $x$ Instructions & 2 & 162,071 & - & - \\
\hline Ss w. groups & 54 & $-162,071$ & - & - \\
\hline Within Ss & $\underline{660}$ & & & \\
\hline Angles & 2 & $24,711,930$ & 147.7 & $<.01$ \\
\hline Order $x$ Angles & 2 & $27,138,939$ & 161.55 & $<.01$ \\
\hline Instructions $x$ Angles & 4 & $13,556,240$ & 80.69 & $<.01$ \\
\hline $\begin{array}{l}\text { Order } x \text { Instructions } \\
\quad x \text { Angles }\end{array}$ & 4 & $13,584,318$ & 80.86 & $<.01$ \\
\hline Angles $\times$ S. w. groups & 108 & 167,994 & & \\
\hline Patterns & 3 & $1,576,209$ & 13.64 & $<.01$ \\
\hline Order x Patterns & 3 & $11,969,236$ & 103.56 & $<.01$ \\
\hline Instructions $x$ Patterns & 6 & $8,148,327$ & 70.50 & $<.01$ \\
\hline $\begin{array}{l}\text { Order } x \text { Instructions } \\
\quad \times \text { Patterns }\end{array}$ & 6 & $2,159,477$ & 18.68 & $<.01$ \\
\hline Patterns $x$ S. W. groups & 162 & 115,568 & & \\
\hline Angles $x$ Patterns & 6 & 791,926 & 2.99 & $<.01$ \\
\hline Order $\times$ Angles $x$ Patterns & 6 & $15,006,594$ & 56.72 & $<.01$ \\
\hline $\begin{array}{l}\text { Instructions } x \text { Angles } \\
\quad x \text { Patterns }\end{array}$ & 12 & $8,629,779$ & 33.00 & $<.01$ \\
\hline $\begin{array}{l}\text { Order } x \text { Instructions } x \\
\text { Angles } x \text { Patterns }\end{array}$ & 12 & 707,238 & 2.67 & $<.01$ \\
\hline $\begin{array}{l}\text { Angles x Patterns } x \\
\text { Ss } w \text {. groups }\end{array}$ & 324 & 264,592 & - & - \\
\hline
\end{tabular}

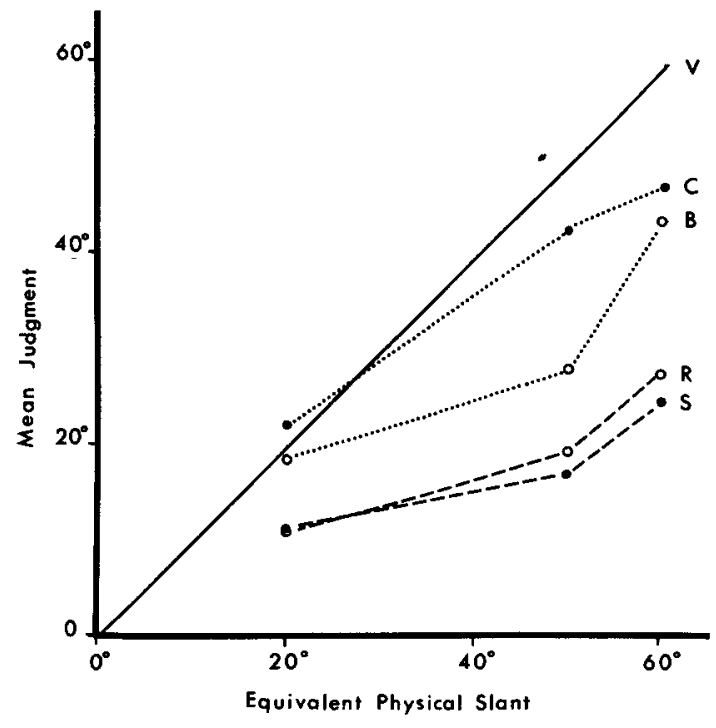

Fig. 2. Mean judgments of slant for the four textured patterns.

$60^{\circ}$ of slant. Thus there were 10 slides presented twice in random order as for the slant judgments. The judgments were made in almost total darkness, but the light was turned on after each judgment to prevent dark adaptation and to enable $\mathrm{E}$ to record the data.

The data recorded were the widths of the light gray comparison rectangle.

Instructions. For slant judgments, the $\mathrm{S}$ was instructed to indicate verbally when the slant of the board that $\mathrm{E}$ turned seemed to match the slant of the patterned display he had just seen.

There were three different instructions for width judgments.

Group A was told: "When you look, you will see a patterned display to the left and a gray rectangle to the right. Your task is to match the width of the gray rectangle to the width of the patterned display. I will make the gray rectangle gradually narrower or wider upon your direction. You will tell me when you are satisfied with the match." (These are ambiguous instructions.)

Group B instructions were: "When you look you will see a patterned display and a gray rectangle. The gray rectangle will always be in the frontal parallel position. The patterned display will be slanted or in the frontal position. Your task is to match the width of the gray rectangle with the width of the patterned display. I will make the gray rectangle narrower or wider upon your direction. You will tell me when you are satisfied with the match." (These are constancy instructions.)

Group C was told: "When you look you will see a patterned display to the left and a gray rectangle to the right. The gray rectangle will always be in the frontal parallel position. The patterned display will 
be slanted or in the frontal position. Your task is to match the width of the gray rectangle with the width you think the patterned standard would be if it were in the frontal plane." (These are projective instructions.)

\section{RESULTS}

Table 1 shows the slant judgments for the angles, patterns and instructional groups. Results of the analysis of variance for the slant judgments are summarized in Table 2. Although there were no significant $F$ values for the effects of order or instructions or for the interactions of these variables with each other, all other interactions were significant at $p<.01$. Furthermore, $F$ ratios for the main effects of angles and patterns were significant with $p<.01)$. Figure 2 shows the slant judgments for the four different textures used. From this graph, it is clear that the particular texture (regular or irregular) has an influence on the slant judgments obtained, with judgments close to the frontal plane with the two irregular textures. This finding is in agreement with Gibson (1950).

The interactions of Order by Angles, Order by Patterns and Order by Angles by Patterns were all significant, with $p<.01$. The resultant curves for the latter interactions were independent of each other. For all four patterns, the mean judgments for the $60^{\circ}$ angle of slant were closer to veridical when slant judgments were made first; for the other angles, order appeared to have no effect on judgments of slant, when averaged over angles and patterns.

Although differential instructions were introduced only in reference to width judgments, the type of instructions had an effect when slant judgments were made after width judgments. Ambiguous instructions (Group A) resulted in the poorest approximation of slant. Group $C$ instructions gave mean judgments closest to the actual slant. The interactions of Instructions by Angles, Instructions by Patterns and Instructions by Angles by Patterns were all significant, $p<.01$. As can be seen in the graphing of the latter interaction (Fig. 3), the brick pattern was judged similarly by Groups $B$ and $C$. The cane pattern was assessed most accurately at $20^{\circ}$ and $45^{\circ}$ with some fall-off at $60^{\circ}$ with Group $B$ instructions, while Group $C$ judged the patterns at a slant closest to the veridical with an evener slope and less fall off at $60^{\circ}$. Group $B$ yielded a better approximation of the irregular splatter and ripple patterns. For all instruction groups the most accurate slant judgments were made with the cane pattern; thus in Group B, a mean setting of $23.21^{\circ}$ matched the photographed slant of $20^{\circ}$, a mean of $45.80^{\circ}$ matched $45^{\circ}$, and $48.16^{\circ}$ was matched to $60^{\circ}$. Over the three instruction groups, the data for the cane pattern were most comparable to the slant data reported by Winnick and Rogoff (1965). These authors reported veridical slant judgments at close

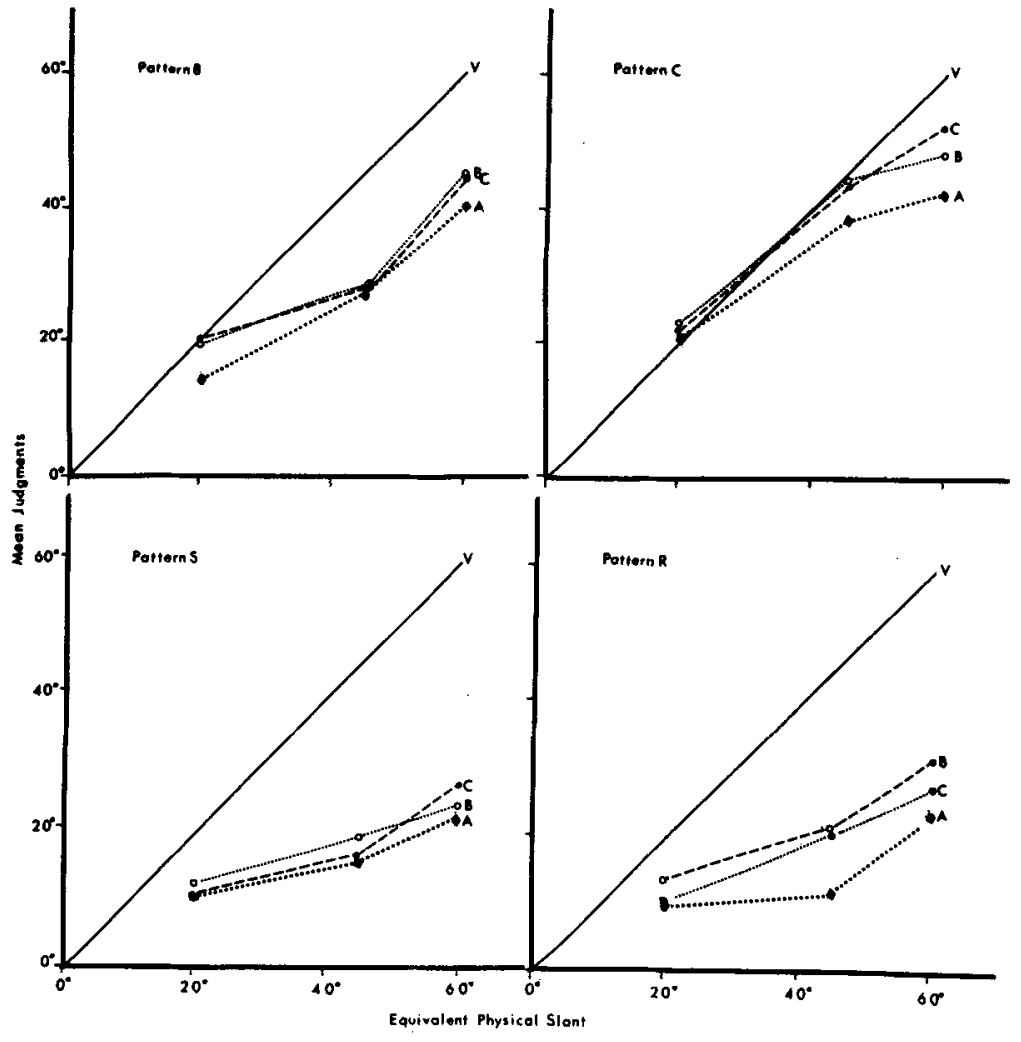

Fig. 3. Mean judgments of slant for the three instructional groups $(A, B, C)$ shown separately for each of the four textured pattems. 
Table 3

Summary Table of Analysis of Variance Performed on Mean Judgments of Shape

\begin{tabular}{|c|c|c|c|c|}
\hline Source & $d f$ & MS & $F$ & $p$ \\
\hline Between Ss & 59 & & & \\
\hline Order & 1 & 412.79 & 5.02 & $<.05$ \\
\hline Instructions & 2 & 578.43 & 7.03 & $<.02$ \\
\hline Order $x$ Instructions & 2 & 69.31 & - & - \\
\hline Ss w. groups & 54 & 82.30 & - & - \\
\hline Within Ss & $\underline{900}$ & & & \\
\hline Angles & 3 & $10,278.32$ & 650.53 & $<.01$ \\
\hline Order $x$ Angles & 3 & 38.13 & 2.41 & - \\
\hline Instructions $x$ Angles & 6 & 30.33 & 14.58 & $<.01$ \\
\hline $\begin{array}{l}\text { Order } x \text { Instructions } x \\
\text { Angles }\end{array}$ & 6 & 52.47 & 3.32 & $<.01$ \\
\hline Ss w. groups & 162 & 15.80 & - & \\
\hline Patterns & 3 & $1,785.67$ & 111.86 & $<.0 .1$ \\
\hline Order $x$ Patterns & 3 & 17.46 & 1.65 & - \\
\hline Instructions $x$ Patterns & 6 & 67.32 & 6.35 & $<.01$ \\
\hline $\begin{array}{l}\text { Order } x \text { Instructions } x \\
\text { Patterns }\end{array}$ & 6 & 13.53 & 1.28 & - \\
\hline Patterns $x$ Ss $w$. groups & 162 & 10.60 & - & \\
\hline Angles $x$ Patterns & 9 & 199.70 & 54.56 & $<.01$ \\
\hline Order $\times$ Angles $x$ Patterns & S 18 & 13.07 & 3.57 & $<.01$ \\
\hline $\begin{array}{l}\text { Order } x \text { Instructions } x \\
\text { Angles } x \text { Patterns }\end{array}$ & 18 & 4.28 & 1.17 & - \\
\hline $\begin{array}{l}\text { Angles } x \text { Patterns } x \\
\text { Ss } w \text {. groups }\end{array}$ & 486 & 3.66 & - & - \\
\hline
\end{tabular}

to $40^{\circ}$ of actual slant; Ss reported slants of from $22^{\circ}$ to $25^{\circ}$ (depending upon stimuli used) to appear to be slanted at $20^{\circ}$ and slants of from $51^{\circ}$ to $57^{\circ}$ to be slanted at $60^{\circ}$; slants of from $68^{\circ}$ to $74^{\circ}$ were reported to correspond to an $80^{\circ}$ slant.

The mean values of the Angle by Patterns interaction for the brick pattern at $20^{\circ}\left(19.82^{\circ}\right)$ and at $45^{\circ}\left(28.07^{\circ}\right)$ may be compared to the results of Gibson (1950). For a similar brick pattern, he obtained readings of $8.6^{\circ}$ for $22^{\circ}$, and of $25.3^{\circ}$ for $45^{\circ}$ with an upward gradient of texture and of $15.9^{\circ}$ for $22^{\circ}$ and $28.6^{\circ}$ for $45^{\circ}$ with a downward gradient of texture. Gibson's results for the irregular texture of $7.8^{\circ}$ for $22^{\circ}$, and $23.9^{\circ}$ for $45^{\circ}$ upward and $7.7^{\circ}$ for $22^{\circ}, 17.9^{\circ}$ for $45^{\circ}$ downward are similar to the mean judgments of $11.05^{\circ}$ for $20^{\circ}$ and $17.13^{\circ}$ for $45^{\circ}$ for irregular texture found in this experiment.

Table 3 summarizes the results of the second analysis of variance for the shape judgments. The main effects of Order and Instructions were both significant; Order, $p<.05$; Instructions, $p<.02$. Their interactions did not reach significance. The variables of Angles and Patterns were significant at $p<.01$. The significant interaction of Order by Angles by Patterns $(p<.01)$ indicates greater underestimations of the width for the patterned materials slanted $60^{\circ}$ from the frontal plane for all patterns when shape judgments were made first. When shape judgments were made first, judgments were closer to projected shape. In the case of instruction Group $C$, the shape judgments made first reveal little differentiation between widths of patterns in frontal parallel position and those slanted $20^{\circ}$ from the frontal plane.

The significant Instructions by Angles by Patterns interaction $(p<.01)$ showed most clearly the relationship of instructions to perception of patterns at a slant. The graphical representation of the brick and cane patterns (Fig. 4) shows judgments intermediate between projective and objective shape for Group $B$ instructions. Group A instructions resulted in judgments closer to projective shape, while the judgments of Group $\mathrm{C}$ were closer to objective shape. For the cane pattern, the three instructional curves were spread evenly between projected and objective shape. Judgments for the random splatter and ripple patterns were mainly below projected shape with width very much underestimated. For the ripple pattern, Group C instructions brought judgments close to projective shape but for random splatter pattern these instructions resulted in an underestimation of even projected shape.

Table 1 summarizes the values of $a-p$, where a equals apparent shape, and $p$, projected shape. It is to be expected that increasing slant will result in increasing compensation as reflected in the value of a-p. From Table 1, it can be seen that the brick pattern in Group A (ambiguous instructions) resulted in the predicted increase only from frontal parallel position to $45^{\circ}$. The predicted increases were found for the two other instruction groups and for the cane pattern for all three instruction groups. Ambiguous instructions did not result in an $a-p$ increase for increased slant in the ripple and random splatter patterns. Constancy instructions resulted in an increase in $a-p$ function for the ripple pattern at $20^{\circ}$ but not at $45^{\circ}$ and $60^{\circ}$. Group $\mathrm{C}$ instructions gave an increase from $0^{\circ}$ through $60^{\circ}$ for the ripple pattern. Projected shapes are matched for the random splatter pattern at $20^{\circ}, 45^{\circ}$, and $60^{\circ}$ with constancy instructions. Group $C$ instructions resulted in an increase in $a-p$ values from $0^{\circ}$ to $45^{\circ}$ and $45^{\circ}$ to $60^{\circ}$.

\section{DISCUSSION}

It was reasoned that, if the shape-slant invariance hypothesis holds true, accuracy in perceiving the increasing slant of a patterned display should be paired with increased compensation in judgments of its width as measured by a-p. A comparison of the results for slant and shape for each pattern (Table 1) shows such a relationship. However, accurate judgments of slant and width are dependent not only on the perception of the cues of pattern and textural gradient but are also subject to experimental manipulation by the use of different instructions.

Joynson and Newson (1962) using vague instruc- 
tions for matching triangles found that the Ss fell into a dichotomy. Sixty-two percent matched for objective shape. The other thirty-eight percent were aware of different possibilities, judging less objectively as the angle of slant was increased. With the introduction of a different, nonobjective set, they showed greater constancy. A pilot study for this experiment using vague instructions found judgments of width close to projected shape. Thus, two additional instructional sets were used in an attempt to produce an effect on width judgments. It was predicted that instructions would affect width judgments systematically and show significance in interaction with the other variables. The specification in interaction $B$ in this experiment, that sometimes the patterned display was in the frontal position and sometimes slanted, moved the mean judgments to a constancy position midway between projective and objective shape for the brick and cane patterns. The judgments for the ripple and irregular splatter pattern showed less underestimation, increasing towards projective shape (see Fig. 4). The explicit instruction (Group C) to move the slanted patterned display back to frontal position mentally before comparing widths resulted in judgments close to objective shape.

The relationship of pattern of slant judgments has been demonstrated by Gibson (1950), Langdon (1953), Flock and Moscatelli (1964) and of slant judgments to width or shape judgments by Beck and Gibson (1955), and Winnick and Rogoff (1965). Gibson (1950) attributed the better slant judgments for a brick pattern to the regularity and familiarity of its adjacent, repeated, rectangular elements. Thus familiarity of shape, repetition, adjacency and linear perspective were the parameters by which he elaborated the variable of texture as a stimulus correlate of perceived optical slant. Epstein and Park (1963) concluded that familiarity of shape cannot be regarded as a relevant variable.

Flock and Moscatelli (1964) have used the notion of congruity of elements in the textured pattern to explain how a gradation. of density may provide information about the slant of a surface. They used Gibson's two patterns as extremes of this congruity variable. Holding the number of elements in each constant, $6 \mathrm{ft}$. by $3 \mathrm{ft}$. patterns with 288 successive spaces, each 3 in. sq., were prepared. The pattern which was intended to be equivalent to Gibson's brick pattern was made up of symmetrical rows and columns of small black squares on a white background. The irregular pattern was constructed of irregular black shapes placed at random within each of the 288 spaces.

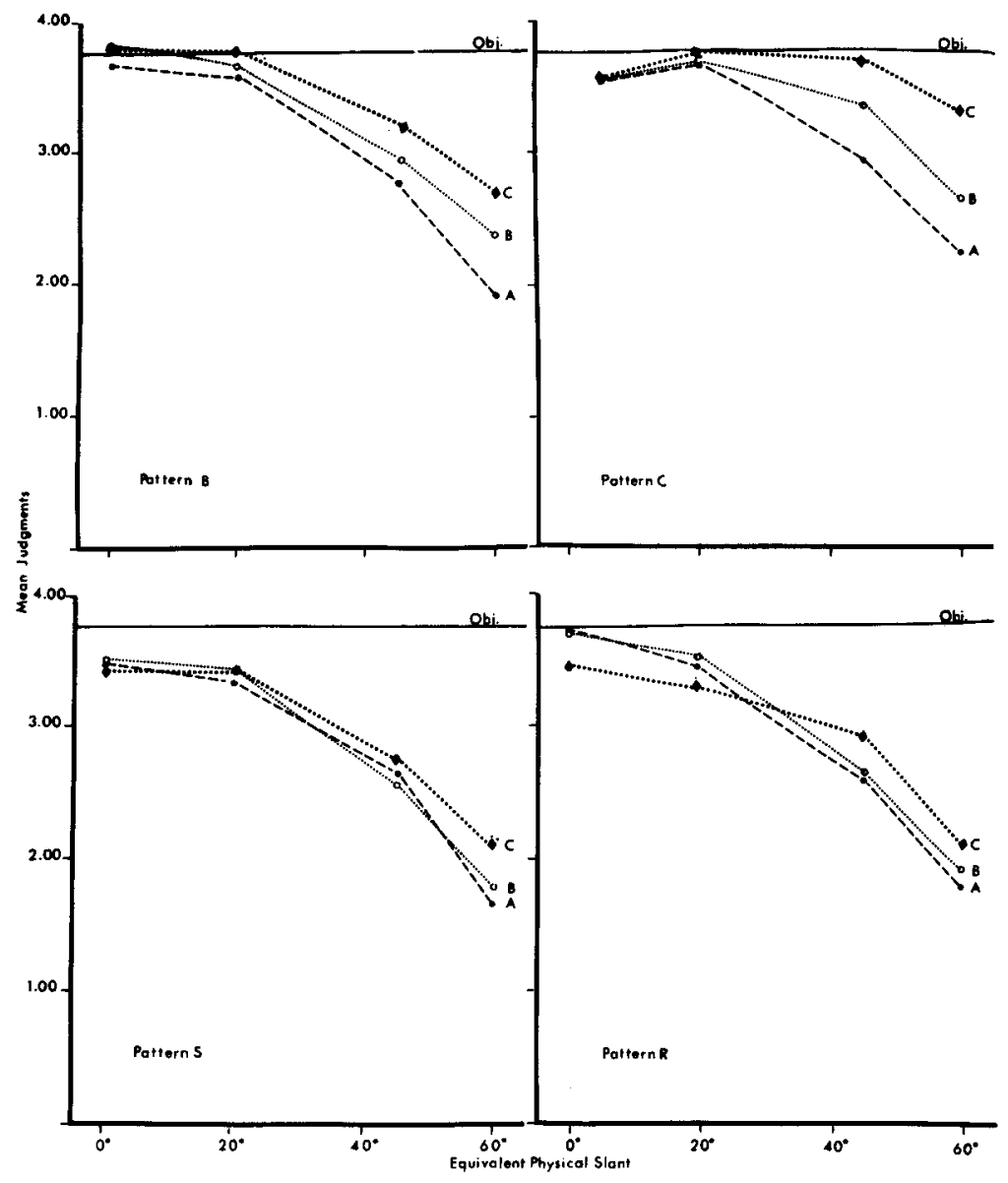

Fig. 4. Mean judgments of width for the three instructional groups $(A, B, C)$ shown separately for the four textured pattems. 
Three textural parameters were varied, congruency of size, angle of slant and the contour of the shapes placed in each cell. The mathematical analysis of these variables from regular to irregular pattern confirmed Gibson's findings of a close relationship between regularity of texture and judgmental error. This was possible without use of the concept of familiarity. The variable of linear perspective played a large role in Gibson's brick pattern but a much smaller one in the Flock and Moscatelli (1964) study, since they used true slants, while Gibson's were nonveridical.

In the present study, slant judgments closest to veridicality and constancy of shape judgments were found for the cane and brick patterns. Congruence of the size of the elements, angles, and shapes was completely satisfied for both of these, more so for the cane pattern. This pattern has a reversible figure-to-ground relationship and a strong linear perspective. Furthermore, the cane pattern is highly redundant, with elements drawn from a small subset of possible patterns (Garner, 1962).

The ripple pattern also had adjacent, repeating, regular elements as did Gibson's (1950), and congruency of size, angle and shape as did that of Flock and Moscatelli (1964). However, the elements were not geometric. They were arranged in an overlapping fashion. Thus linear perspective was not clear. Perhaps it is necessary for the congruent shapes also to be symmetrical. This pattern was superior to the random pattern for slant and shape judgments, but not as good as the brick pattern which satisfied the congruency requirements and in addition had clear linear perspective.

Discrepancies were found between the slant judgments for the brick and splatter patterns in this experiment and those for similar patterns of Gibson (1950). These are probably due to differences in the display conditions in the two studies; Gibson presented the textured array through a double stop, yielding a round image, while in the present study the projected images were rectangular. Interested only in slant judgments, Gibson was able to limit the S's angle of vision so that only the small central portion of the pattern could be seen. Since width judgments also were sought in the present experiment, the angular field of view was enlarged so that $S$ could see the edges of the rectangular textured patterned display.

In summary, the results of this experiment support the relationship of texture gradient to slant perception (Gibson, 1950) and confirm the conclusion of Flock and Moscatelli (1964) that there is a "close relationship between the irregularities of textural parameters and judgmental errors." Furthermore, it has been found that judgments of width vary and interact with accuracy of slant perception and instructional set.

\section{References}

Beck, J., \& Gibson, J. J. The relationship of apparent shape to apparent slant in the perception of objects. J. exp. Psychol., $1955,50,125-133$.

Epstein, W., \& Park, J. Shape constancy: Functional relationships and theoretical formulations. Psychol. Bull., 1963, 60, 265-288.

Flock, H. R., \& Moscatelli, A. Variables of surface texture and visual space perceptions. Percept. mot. Skills, 1964, 19, 327-335.

Gamer, W. R. Uncertainty and structure as psychological concepts. New York: Wiley, 1962.

Gibson, J. J. The perception of visual surfaces. Amer. J. Psychol., $1950,63,367-384$.

Joynson,. R. B., \& Newson, L. J. The perception of shape as a function of inclination. Brit. J. Psychol., 1962, 53, 1-15.

Langdon, J. The perception of changing shape. Quart. J. exp. Psychol., 1951, 3, 157-165.

Winer, B. J. Statistical principles in experimental design. New York: McGraw-Hill, 1962.

Winnick, W. A., \& Rogoff, I. Role of apparent slant in shape judgments, J. exp. Psychol., 1965, 69, 554-563.

Winnick, W. A., \& Rosen, B. E. Shape-slant relations under reduction conditions. Percept. \& Psychophys., 1966, 1, 157-160.

\section{Note}

1. Based upon a thesis submitted by the first author to the Graduate Division of Queens College of the City University of New York, in partial fulfillment of the requirements for the degree of Master of Arts. The authors acknowledge with thanks the assistance of Gerard Bruder.

(Accepted for publication January 23, 1967.) 